\title{
Occupation and Obesity: Effect of Working Hours on Obesity by Occupation Groups
}

\author{
Hande Barlin ${ }^{1} \&$ Murat Anil Mercan ${ }^{2}$ \\ ${ }^{1}$ Faculty of Business Administration, Department of Economics, Gebze Technical University, Kocaeli, Turkey \\ ${ }^{2}$ Faculty of Business Administration, Department of Economics, Gebze Technical University, Kocaeli, Turkey \\ Correspondence: Hande Barlin, Faculty of Business Administration, Department of Economics, Gebze Technical \\ University, Kocaeli, Turkey.
}

Received: February 3, 2016

Accepted: February 24, 2016

Available online: February 25, 2016

doi:10.11114/aef.v3i2.1351

URL: http://dx.doi.org/10.11114/aef.v3i2.1351

\begin{abstract}
Despite leveling off, United States is faced with high prevalence of obesity. Obesity epidemic is an important public health concern imposing pressures on social support schemes, leading to productivity losses and threatening quality of life of the people living with it. As occupations take up good portion of adult's daily life and have close relations with socio-economic factors and behavioral traits, understanding the relationships between occupations and obesity aids efforts fighting with the epidemic. In this respect, taking working hours into consideration, present study investigates the probability of being obese in 40 occupational groupings and identifies six occupation groups reducing the risk of obesity. This study is a first attempt to examine the effect of working hours on obesity by occupation groups in the United States.
\end{abstract}

Keywords: Occupation, Working hours, Obesity, Health, Weight, Labor

\section{Introduction}

Obesity epidemic is an unprecedented challenge that the American society face. It is a public health matter, which has implications both at economic and social sphere. It does not only impose pressures on social support schemes and leads to productivity losses, but also threatens quality life of the people that are living with it.

Starting from mid 1970s, especially throughout 1980s and 1990s United States witnessed a sharp increase in the obesity prevalence. This trend slowed down in 2000s (Flegal, Carroll, Kit, \& Ogden, 2012; Ogden, Carroll, Kit \&Flegal, 2014), nevertheless reached a prevalence of $\% 34.9$ (defined as body mass index (BMI) equal to or greater than 30) among adults in 2011-2012. Obesity prevalence shows significant variance by sex, age and race/ethnicity in the United States. Females, non-Hispanic blacks and middle age people have the highest prevalence of grade III obesity (BM equal to or greater than 40) within their own groups (Ogden et al., 2014).

Obesity is associated with higher likelihood of developing variety of chronic diseases and non-chronic diseases ranging from type II diabetes and coronary heart diseases to breast and colon cancer (Gu et al., 2014). Moreover, it is linked with disability, morbidity and mortality (Solovieva, Lallukka, Virtanen, \&Viikari-Juntura, 2013). It leads to productivity losses, which may result from its association with absenteeism/sick leave (Moreau, 2004), work injuries (Lin,Verma, \& Courtney, 2013), work limitation (Forhan, Law, , Vrkljan\& Taylor, 2010), presenteeism (Wang, McPherson, Marsh, Gortmaker\& Brown, 2011), early retirement (Cawley, Rizzo \& Haas, 2007) and premature death (Coditz, 1999).

These associations, which are negative in nature, translate themselves to direct and indirect costs. While, direct costs stems from treatment of diseases related with obesity, indirect costs are linked with loss of productivity (Coditz, 1999). High prevalence of obesity with its concomitant health problems coupled with aging population imposes pressures on social support schemes, especially health care systems. By 2030 a yearly increase of $\$ 48-66$ billion in obesity related healthcare costs and several times larger productivity losses were estimated for the US (Wang et al., 2011).

Even though some cases of obesity are linked with genetic and metabolic reasons, the epidemic itself is related to behavioral determinants (Bonde\&Viikari-Juntura, 2013) and social and physical environment (Sturm \&An, 2014). Epidemic has been attributed to "mechanization, urbanization, motorization, and computerization" as well as increase in production of more processed accessible lower cost energy dense foods and consequent rise in food energy supply 
pushing up population's energy intake (Swinburn et al., 2011). Moreover, general tendency of pursuit of passive leisure activities (Maruf\&Udoji, 2015) and increase in value of time, which led to changes in eating habits and physical activity choices (Chou, Grossman \&Saffer, 2004), also contributed to the epidemic.

In general, excess energy intake over energy expenditure leads to weight gain and excessive weight gain eventuates in obesity (Bonde\&Viikari-Juntura, 2013). At the level of individuals habits and daily behaviors regarding eating and physical activity determines how many calories that an individual intakes and burns. As a worker spends one third of a day at work, daily routines associated with work and occupation is thought to contribute to the process of energy balance and weight gain (Solovieva et al., 2013) and thereby to obesity. Accordingly various studies were conducted to investigate the relation between work/occupation and obesity for the US and other countries. Nevertheless, most of the studies focus on the prevalence of obesity within occupations and to some extent related health behaviors. Even though there are several studies, which investigate the relationship between obesity and working hours (Au, Hauck, \& Hollingsworth, 2013; Mercan, 2014), there is no previous study investigating the effect of working hours on obesity by occupation groups. This study is first to examine the probability of being obese in 40 occupational groups focusing on the effect of working hours.

\section{Obesity and Occupation}

Occupations are closely related with specific socio-economic factors and behavioral traits. Therefore, they carry potential for influencing the risk for obesity (Allman-Farinelli, Chey, Merom\& Bauman, 2010). Moreover, most of the time nature of occupations dictates how much physical activity is involved (Kajitani, 2015). For instance while some jobs like construction laboring demands workers to be physically active (Steeves et al. 2015), some other jobs like truck driving imposes extended sedentary time (Moreno, Louzada, Teixeira, Borges \&Lorenzi, 2006).

Furthermore, position held, overtime, stress related with the job (Caban, Le, Fleming, Gomez-Marin, LeBlanc \& Pitman, 2005), shift work (Caruso, 2014; Ferguson et al., 2015), long work hours (Di Milia, \& Mummery, 2009; Jang, Kim, Lee, Myong\& Koo, 2013), sedentary work (Choi et al., 2010), hostile work environment and job insecurity (Luckhaupt, Cohen, Li \&Calver, 2014) as well as working at medium sized enterprises (Park, Pan, \& Lankford, 2014) increases the risk of obesity. In addition, as occupations and social status are associated shared perceptions concerning obesity may prevail among group members (Wardle, Waller \& Jarvis, 2002). This may facilitate internalization of obesity or its rejection depending on the group's perception. For instance it is believed that while white collar workers generally endorse healthy lifestyle and regard being slim as a class norm, lower occupational classes may take obesity as ordinary (Shaikh, Sikora, Siahpush\& Singh, 2015).

On the other hand physically demanding occupations lowers the likelihood of obesity compared with jobs that are not physically demanding (Bonauto, Lu, \& Fan, 2014; Steeves, Bassett, Thompson, \& Fitzhugh, 2012). Moreover, consumption of adequate amount of fruits and vegetables (Luckhaupt et al., 2014) and undertaking adequate leisure time physical activity decrease the likelihood of obesity (King et al., 2001; Bonauto et al., 2014). Related to occupations, education also reduces the risk of obesity (Wardle et al., 2002) and it is negatively associated with BMI (Flegal, Harlan \& Landis, 1988; Galobardes, Morabia\&Benstein, 2000).

Furthermore, longer work hours are related to weight gain (Au \& Hollingsworth, 2011; Mercan, 2014) and higher body mass index (DiMilla, 2009). It is also associated with unhealthy behaviors; for example smoking, consumption of alcohol and coffee, having unbalanced diets and inadequate leisure time physical activity. (Jang et al., 2013; Shaikh et al., 2015; Caruso, 2014; Escoto, Laska, Larson, Neumark-Sztainer and Hannan, 2012; Fernandes, 2013). Furthermore, lack of time for recovery impedes the well functioning of the physiological process, paving the way for many diseases and fatigue. (Caruso, 2006)

Various studies have put forth that prevalence of obesity varies by occupation in the United States (Caban et al., 2005; Bonauto et al., 2014; Gu et al., 2014; Luckhaupt et al.,2014; Shaikh et.al, 2015). Even though each study examines a different period and different grouping of occupations, generally obesity prevalence among motor vehicle operators, protective services, cleaning and building services as well as healthcare support is high. On the other hand health diagnosing occupations is among the occupation with the lowest prevalence of obesity prevalence.

\section{Data and Methodology}

In this study, obesity data used is from the National Health and Nutrition Examination Survey (NHANES) between 2003 and 2004. It is an annual nationwide health survey conducted in the US, which examines a nationally representative sample of about 5,000 persons. NHANES public use data files employs 2 digit codes in occupational coding. These two digits codes, which are in line with Standard Occupational Classification of US Census Bureau, pertain to 40 broad (major) occupational groups.

In the study BMI (weight in $\mathrm{kg} /$ height $\mathrm{x}$ height in $\mathrm{m} 2$ ) was used to determine obesity. Measurements classified as obese were BMIs that were equal to or greater than 30 . Accordingly, 35 percent of the sample is obese. 
Table1. Summary Statistics

\begin{tabular}{lcccc}
\hline & Mean & Std. Dev. & Min & Max \\
\cline { 2 - 5 } Obese & 0.35 & 0.48 & 0 & 1 \\
Male & 0.54 & 0.50 & 0 & 1 \\
Age & 39.73 & 13.44 & 16 & 85 \\
White & 0.71 & 0.45 & 0 & 1 \\
Black & 0.10 & 0.30 & 0 & 1 \\
US born & 0.84 & 0.37 & 0 & 1 \\
More than high school graduate & 0.60 & 0.49 & 0 & 1 \\
Married & 0.56 & 0.50 & 0 & 1 \\
\hline $\mathrm{N}$ & & 2816 &
\end{tabular}

Table 1 shows summary statistics for the sample. 54 percent of the sample is men and 71 percent of the sample is white. In the sample, the average age is about 40 . Furthermore, 84 percent of the sample is US born natives and 56 percent of the sample is married. Moreover, 60 percent of the sample have a degree more than a high school.

In the study a probit model was used to investigate the probability of being obese in occupation groups. The model is:

$$
\mathrm{D}_{\text {obese }}=\beta_{0}+\beta_{1} \text { Occupation }+\beta_{2} \text { Occupation*Working Hours }+\mathrm{A}+\varepsilon
$$

where $\mathrm{D}_{\text {obese }}$ equals to 1 , if the person is obese, Occupation includes occupation dummies, Occupation*Working Hours is an interaction variable between occupation and working hours, and A includes male, age, white, black, US born natives, more than high school graduates, married, and annual family income covariates.

\section{Results}

Table 2 shows the marginal effects from the probit model. According to the results, there are six occupation groups, which statistically significant reduce the probability of being obese: Engineers, architects and scientists, Writers, artists, entertainers, and athletes; Construction trades; Other mechanics and repairers; Fabricators, assemblers, inspectors, and samplers; and Freight, stock, and material movers, hand. The results suggests that members of these six occupations are inclined to loose weight as they work long hours.

Table 2. Marginal Effects

\begin{tabular}{lcc}
\hline & Coefficient & Std. Err. \\
\hline Management related occupations & -0.07 & 0.07 \\
Engineers, architects and scientists & $-0.17 * * *$ & 0.07 \\
Health diagnosing, assessing and treating occupations & 0.01 & 0.08 \\
Teachers & -0.05 & 0.08 \\
Writers, artists, entertainers, and athletes & $-0.16^{*}$ & 0.09 \\
Other professional specialty occupations & -0.06 & 0.07 \\
Technicians and related support occupations & 0.04 & 0.08 \\
Supervisors and proprietors, sales occupations & 0.05 & 0.08 \\
Sales representatives, finance, business, \& commodities ex. Retail & -0.06 & 0.08 \\
Sales workers, retail and personal services & -0.05 & 0.06 \\
Secretaries, stenographers, and typists & -0.01 & 0.10 \\
Information clerks & -0.10 & 0.09 \\
Records processing occupations & 0.02 & 0.09 \\
Material recording, scheduling, and distributing clerks & 0.04 & 0.09 \\
Miscellaneous administrative support occupations & -0.03 & 0.07 \\
Private household occupations & -0.18 & 0.10 \\
Protective service occupations & -0.04 & 0.10
\end{tabular}


Waiters and waitresses

$\begin{array}{cc}-0.11 & 0.09 \\ -0.02 & 0.08 \\ -0.11 & 0.08 \\ -0.03 & 0.08 \\ -0.07 & 0.08 \\ -0.09 & 0.08 \\ 0.01 & 0.16 \\ -0.15 & 0.15 \\ 0.10 & 0.10 \\ -0.02 & 0.13 \\ -0.15 * & 0.09 \\ -0.21 * * * & 0.07 \\ -0.11 & 0.08 \\ -0.12 & 0.13 \\ 0.09 & 0.12 \\ -0.19 * * & 0.09 \\ -0.09 & 0.08 \\ -0.06 & 0.12 \\ -0.09 & 0.12 \\ -0.16 & 0.15 \\ -0.25 * * * & 0.08 \\ -0.06 & 0.12\end{array}$

Cooks

Miscellaneous food preparation and service occupations

Health service occupations

Cleaning and building service occupations

Personal service occupations

Farm operators, managers, and supervisors

Farm and nursery workers

Related agricultural, forestry, and fishing occupations

Vehicle and mobile equipment mechanics and repairers

Other mechanics and repairers

Construction trades

Extractive and precision production occupations

Textile, apparel, and furnishings machine operators

Machine operators, assorted materials

Fabricators, assemblers, inspectors, and samplers

Motor vehicle operators

Other transportation and material moving occupations

Construction laborers

Laborers, except construction

Freight, stock, and material movers, hand

Other helpers, equipment cleaners, hand packagers and laborers

$* * * \mathrm{p}<0.01 * * \mathrm{p}<0.05 * \mathrm{p}<0.1$

There is a strong relationship between education and health (Silles, 2009). Proportion of workers with education higher than high school varies. 98 percent of Engineers, architects and scientists, 85 percent of Writers, artists, entertainers, and athletes, 52 percent of Other mechanics and repairers, 35 percent of Construction trades, 38 percent of Fabricators, assemblers, inspectors, and samplers, 47 percent of Freight, stock, and material movers, hand have a degree more than a high school. It suggests that highly educated workforce such as Engineers, architects and scientists, are less likely to be obese. It is an important result for public health.

\section{Discussion}

The study reveals that workers in some occupations have lower likelihood for obesity. When the effect of working hours are considered, six occupation groups significantly reduce the probability of being obese. These occupation groups are Engineers, architects and scientists; Writers, artists, entertainers, and athletes; Construction trades; Other mechanics and repairers; Fabricators, assemblers, inspectors, and samplers and Freight, stock, and material movers, hand.

Exact mechanism leading to reduced risk of obesity for these six occupations are not known. Two of the possible explanations of the relation rests with the nature of the occupations. Members of the two occupation groups, namely Engineers, architects and scientists and Writers, artists, entertainers and athletes, are highly educated. This result is in conformity with Proper and Hildebrandt (2014), which found that the occupations with lower BMIs were also the occupations, of which workers' education level were higher. It is also in line with Wardle et al. (2002), where the study reviled that higher education reduces the likelihood of obesity. These may be the outcome of education's role in easing the process of health information's interpretation (Galobardes, Morabia\& Bernstein, 2000) and enabling people to adopt healthy lifestyles (Mirowski\& Ross, 1998), such that people with higher education consume more fruits and vegetables (Thompson et al., 1999). In addition these occupations are also among the occupational groups with higher proportion of workers having adequate leisure time physical activity (Caban-Martinez et al., 2007).

On the other hand, Other mechanics and repairers, Construction trades and Freight, stock and material movers, hand are physically demanding occupations and have been classified as occupations with high occupation activity by Steeves et al. (2015). These types of occupations may protect workers from obesity (Bonauto, 2014; King et al., 2001) as the amount of energy burned would be higher compared with sedentary jobs. It is estimated that physically demanding 
occupations which involve lifting and carrying has $2.4 \%$ lower BMI in comparison with sedentary jobs (Bockerman, Johansson, Jousilahti\&Uutela, 2008).

Furthermore, three of the six occupations, Engineers, architects and scientists, Construction trades as well as Writers, artists, entertainers and athletes are among occupation groups of which good portion of members can be characterized with high cardiovascular fitness (Lewis et al., 2011). This condition implies that members of these occupation groups pursue good health behaviors such as physical activity (Blumenthal et al, 1998;Kennedy et al., 2007), which plays a key role in preventing undesired weight gain (Erlichman, Kerbey\& James, 2002)

As obesity is an important public health concern, there is need for further research, which would aid slowing down of the obesity epidemic. Further research should focus on these six occupations and identification of determinants of relations between these occupations and lower BMI.

\section{Conclusion}

Obesity is an important public health matter with economic and social implications. Using a nationwide representative survey for the United States, the study identified six occupation groups reducing the risk of obesity. While exact mechanism leading to reduced obesity risk is not known, two possible explanations rests with the nature of the occupations and profile of the members of the occupation groups. Accordingly, while some of the identified occupations are physically demanding and have been classified as occupation groups with high occupational activity, the others required members to be highly educated. Further research focusing on these six occupations are needed to determine factors leading to lower likelihood for obesity.

\section{References}

Allman-Farinelli, M. A., Chey, T., Merom, D., \& Bauman, A. E. (2010). Occupational risk of overweight and obesity: an analysis of the Australian Health Survey. Journal of Occupational Medicine and Toxicology, 5. http://dx.doi.org/10.1186/1745-6673-5-14

Au, N., \& Hollingsworth, B. (2011). Employment patterns and changes in body weight among young women. Preventive Medicine, 52(5), 310-316. http://dx.doi.org/10.1016/j.ypmed.2011.03.006

Au, N., Hauck, K., \& Hollingsworth, B. (2013). Employment, work hours and weight gain among middle-aged women. International Journal of Obesity, 37(5), 718-724. http://dx.doi.org/10.1038/ijo.2012.92

Blumenthal, J. A., Emery, C. F., Walsh, M. A., Cox, D. R., Kuhn, C. M., Williams, R. B., \& Williams, R. S. (1988).Exercise training in healthy type-A middle age men- Effects on behavioral and cardiovascular responses. Psychosomatic Medicine, 50(4), 418-433.

Bockerman, P., Johansson, E., Jousilahti, P., \&Uutela, A. (2008). The physical strenuousness of work is slightly associated with an upward trend in the BMI. Social Science \& Medicine, 66(6), 1346-1355. http://dx.doi.org/ 10.1016/j.socscimed.2007.12.015

Bonauto, D. K., Lu, D., \& Fan, Z. J. (2014). Obesity prevalence by occupation in Washington State, behavioral risk factor surveillance system.Preventing Chronic Disease, 11.http://dx.doi.org/10.5888/pcd11.130219

Bonde, J. P. E., \& Viikari-Juntura, E. (2013). The obesity epidemic in the occupational health context.Scandinavian Journal of Work Environment \& Health, 39(3), 217-219. http://dx.doi.org/10.5271/sjweh.3362

Caban, A. J., Lee, D. J., Fleming, L. E., Gomez-Marin, O., LeBlanc, W., \& Pitman, T. (2005). Obesity in US workers: The National Health Interview Survey, 1986 to 2002. American Journal of Public Health, 95(9), 1614-1622. http://dx.doi.org/10.2105/ajph.2004.050112

Caban-Martinez, A. J., Lee, D. J., Fleming, L. E., LeBlanc, W. G., Arheart, K. L., Chung-Bridges, K., . . Pitman, T. (2007). Leisure-time physical activity levels of the US workforce. Preventive Medicine, 44(5), 432-436. http://dx.doi.org/10.1016/j.ypmed.2006.12.017

Caruso, C. C. (2006). Possible broad impacts of long work hours.Industrial Health, 44(4), 531-536. http://dx.doi.org/10.2486/indhealth.44.531

Caruso, C. C. (2014). Negative impacts of shiftwork and long work hours.Rehabilitation Nursing, 39(1), 16-25. http://dx.doi.org/10.1002/rnj.107

Cawley, J., Rizzo, J. A., \& Haas, K. (2007). Occupation-specific absenteeism costs associated with obesity and morbid obesity. Journal of Occupational and Environmental Medicine, 49(12), 1317-1324. http://dx.doi.org/10.1097/JOM.0b013e31815b56a0

Choi, B., Schnall, P. L., Yang, H., Dobson, M., Landsbergis, P., Israel, L., . . Baker, D. (2010). Sedentary work, low physical job demand, and obesity in US Workers. American Journal of Industrial Medicine, 53(11), 1088-1101. 
http://dx.doi.org/10.1002/ajim.20886

Chou, S. Y., Grossman, M., \& Saffer, H. (2004). An economic analysis of adult obesity: results from the Behavioral Risk Factor Surveillance System. Journal of Health Economics, 23(3), 565-587. http://dx.doi.org/10.1016/j.jhealeco.2003.10.003

Colditz, G. A. (1999). Economic costs of obesity and inactivity. Medicine and Science in Sports and Exercise, 31(11), S663-S667. http://dx.doi.org/10.1097/00005768-199911001-00026

Di Milia, L., \& Mummery, K. (2009). The association between job related factors, short sleep and obesity. Industrial Health, 47(4), 363-368.

Erlichman, J., Kerbet, A. L., \& James W. P. T. (2002).Physical activity and its impact on health outcomes. Paper 2: Prevention of unhealthy weight gain and obesity by physical activity: an analysis of the evidence. Obesity Reviews, 34(4), 273-87.10.1046/j.1467-789X.2002.00078.x

Escoto, K. H., Laska, M. N., Larson, N., Neumark-Sztainer, D., \&Hannan, P. J. (2012). Work hours and perceived time barriers to healthful eating among young adults. American Journal of Health Behavior, 36(6), 786-796. http://dx.doi.org/10.5993/ajhb.36.6.6

Ferguson, T. W., Andercheck, B., Tom, J. C., Martinez, B. C., \&Stroope, S. (2015). Occupational conditions, self-care, and obesity among clergy in the United States. Social Science Research, 49, 249-263. http://dx.doi.org/10.1016/j.ssresearch.2014.08.014

Flegal, K. M., Carroll, M. D., Kit, B. K., \& Ogden, C. L. (2012).Prevalence of obesity and trends in the distribution of body mass index among US adults, 1999-2010.Jama-Journal of the American Medical Association, 307(5), 491-497. http://dx.doi.org/10.1001/jama.2012.39

Flegal, K. M., Harlan, W. R., \& Landis, J. R. (1988).Secular trends in body-mass index and skinfold thickness with socioeconomic-factors in young-adult women.American Journal of Clinical Nutrition, 48(3), 535-543.

Forhan, M. A., Law, M. C., Vrkljan, B. H., \& Taylor, V. H. (2010).The experience of participation in everyday occupations for adults with obesity.Canadian Journal of Occupational Therapy-Revue Canadienne D Ergotherapie, 77(4), 210-218. http://dx.doi.org/10.2182/cjot.2010.77.4.3

Galobardes, B., Morabia, A., \& Bernstein, M. S. (2000). The differential effect of education and occupation on body mass and overweight in a sample of working people of the general population.Annals of Epidemiology, 10(8), 532-537. http://dx.doi.org/10.1016/s1047-2797(00)00075-2

Gu, Ja K., Charles, Luenda E., Bang, Ki Moon, Ma, Claudia C., Andrew, Michael E., Violanti, John M., \&Burchfiel, Cecil M. (2014). Prevalence of obesity by occupation among US workers: The National Health Interview Survey 2004-2011. Journal of Occupational and Environmental Medicine, 56(5), 516-528. http://dx.doi.org/10.1097/jom.0000000000000133

Jang, T., Kim, H., Lee, H., Myong, J., \& Koo, J. (2013). Long work hours and obesity in Korean adult workers. Journal of Occupational Health, 55(5), 359-366.

Kajitani, S. (2015). Which is worse for your long-term health, a white-collar or a blue-collar job? Journal of the Japanese and International Economies, 38, 228-243. http://dx.doi.org/10.1016/j.jjie.2015.09.002

Kennedy, R. A., Boreham, C. A. G., Murphy, M. H., Young, I. S., \&Mutrie, N. (2007).Evaluating the effects of a low volume stairclimbingprogramme on measures of health-related fitness in sedentary office workers.Journal of Sports Science and Medicine, 6(4), 448-454.

King, G. A., Fitzhugh, E. C., Bassett, D. R., McLaughlin, J. E., Strath, S. J., Swartz, A. M., \& Thompson, D. L. (2001). Relationship of leisure-time physical activity and occupational activity to the prevalence of obesity.International Journal of Obesity, 25(5), 606-612. http://dx.doi.org/10.1038/sj.ijo.0801583

Lin, T., Verma, S. K., \& Courtney, T. K. (2013). Does obesity contribute to non-fatal occupational injury? Evidence from the National Longitudinal Survey of Youth.Scandinavian Journal of Work Environment \& Health, 39(3), 268-275. http://dx.doi.org/10.5271/sjweh.3347

Luckhaupt, S. E., Cohen, M. A., Li, J., \& Calvert, G. M. (2014). Prevalence of obesity among U.S. workers and associations with occupational factors.American Journal of Preventive Medicine, 46(3), 237-248. http://dx.doi.org/10.1016/j.amepre.2013.11.002

Maruf, F. A., \&Udoji, N. V. (2015).Prevalence and socio-demographic determinants of overweight and obesity in a Nigerian population.Journal of Epidemiology, 25(7), 475-481. http://dx.doi.org/10.2188/jea.JE20140099

Mercan, M. A. (2014). A research note on the relationship between long working hours and weight gain for older 
workers in the United States.Research on Aging, 36(5), 557-567. http://dx.doi.org/10.1177/0164027513510324

Mirowsky, J., \& Ross, C. E. (1998).Education, personal control, lifestyle and health - A human capital hypothesis.Research on Aging, 20(4), 415-449. http://dx.doi.org/10.1177/0164027598204003

Moreau, M., Valente, F., Mak, R., Pelfrene, E., de Smet, P., De Backer, G., \&Kornitzer, M. (2004). Obesity, body fat distribution and incidence of sick leave in the Belgian workforce: the Belstress study. International Journal of Obesity, 28(4), 574-582. http://dx.doi.org/10.1038/sj.ijo.0802600

Moreno, C. R. C., Louzada, F. M., Teixeira, L. R., Borges, F., \&LorenziFilho, G. (2006). Short sleep is associated with obesity among truck drivers. Chronobiology International, 23(6), 1295-1303. http://dx.doi.org/10.1080/07420520601089521

Ogden, C. L., Carroll, M. D., Kit, B. K., \&Flegal, K. M. (2014).Prevalence of childhood and adult obesity in the United States, 2011-2012.Jama-Journal of the American Medical Association, 311(8), 806-814. http://dx.doi.org/10.1001/jama.2014.732

Park, S., Pan, L., \& Lankford, T. (2014). Relationship between employment characteristics and obesity among employed U.S. Adults. American Journal of Health Promotion, 28(6), 389-396. http://dx.doi.org/10.4278/ajhp.130207-QUAN-64

Proper, K. I., \& Hildebrandt, V. H. (2010). Overweight and obesity among Dutch workers: differences between occupational groups and sectors. International Archives of Occupational and Environmental Health, 83(1), 61-68. http://dx.doi.org/10.1007/s00420-009-0438-1

Shaikh, R. A., Sikora, A., Siahpush, M., \& Singh, G. K. (2015). Occupational variations in obesity, smoking, heavy drinking, and non-adherence to physical activity recommendations: Findings from the 2010 National Health Interview Survey. American Journal of Industrial Medicine, 58(1), 77-87. http://dx.doi.org/10.1002/ajim.22405

Silles, M. A. (2009). The causal effect of education on health: Evidence from the United Kingdom. Economics of Education Review, 28(1), 122-128. http://dx.doi.org/10.1016/j.econedurev.2008.02.003

Solovieva, S., Lallukka, T., Virtanen, M., \& Viikari-Juntura, E. (2013). Psychosocial factors at work, long work hours, and obesity: a systematic review. Scandinavian Journal of Work Environment \& Health, 39(3), 241-258. http://dx.doi.org/10.5271/sjweh.3364

Steeves, J. A., Bassett, D. R., Jr., Thompson, D. L., \& Fitzhugh, E. C. (2012).Relationships of occupational and non-occupational physical activity to abdominal obesity.International Journal of Obesity, 36(1), 100-106. http://dx.doi.org/10.1038/ijo.2011.50

Steeves, J. A., Tudor-Locke, C., Murphy, R. A., King, G. A., Fitzhugh, E. C., \& Harris, T. B. (2015). Classification of occupational activity categories using accelerometry: NHANES 2003-2004. International Journal of Behavioral Nutrition and Physical Activity, 12. http://dx.doi.org/10.1186/s12966-015-0235-z

Sturm, R., \& An, R..(2014). Obesity and economic environments.Ca-a Cancer Journal for Clinicians, 64(5), 337-350. http://dx.doi.org/10.3322/caac.21237

Swinburn, B. A., Sacks, G., Hall, K. D., McPherson, K., Finegood, D. T., Moodie, M. L., \&Gortmaker, Steven L. (2011). Obesity 1 The global obesity pandemic: shaped by global drivers and local environments. Lancet, 378(9793), 804-814. http://dx.doi.org/10.1016/S0140-6736(11)60813-1

Thompson, B., Demark-Wahnefried, W., Taylor, G., McClelland, J. W., Stables, G., Havas, S., . . Cohen, N. (1999). Baseline fruit and vegetable intake among adults in seven 5 A Day study centers located in diverse geographic areas.Journal of the American Dietetic Association, 99(10), 1241-1248. http://dx.doi.org/10.1016/s0002-8223(99)00306-5

Wang, Y. C., McPherson, K., Marsh, T., Gortmaker, S. L., \& Brown, M..(2011). Obesity 2 Health and economic burden of the projected obesity trends in the USA and the UK.Lancet, 378(9793), 815-825.

Wardle, J., Waller, J., \& Jarvis, M. J. (2002).Sex differences in the association of socioeconomic status with obesity.American Journal of Public Health, 92(8), 1299-1304. http://dx.doi.org/10.2105/ajph.92.8.1299

\section{(cc) $\mathrm{Br}$}

This work is licensed under a Creative Commons Attribution 3.0 License. 